\title{
VIDEO ESSAYS: CURATING AND TRANSFORMING FILM EDUCATION THROUGH ARTISTIC RESEARCH
}

\author{
ESTRELLA SENDRA*
}


INTERNATIONAL JOURNAL OF FILM AND MEDIA ARTS (2020) Vol. 5, No. 2

Estrella is a scholar, teacher, filmmaker, journalist and festival organiser.

Estrella has made a number of documentary films, including Témoignages de l'autre côté (2011), national winner in Spain of the European Charlemagne Youth Prize, Diabel Cissokho: the story of a griot (2014), and Témoignages.. "waa suñu gaal" (2016, with Mariama Badji).

www.estrellasendra.com

\section{Corresponding Author:}

Estrella Sendra: es29@soas.ac.uk

Office 404, Main Building

SOAS, University of London

Thornhaugh Street, Russell Square, London WC1H OXG

Paper submitted: $27^{\text {th }}$ March 2020

Accepted for publication: $26^{\text {th }}$ September 2020

Published Online: $13^{\text {th }}$ November 2020 


\title{
Acknowledgements
}

This article is dedicated to all my SOAS undergraduate and postgraduate class members of the academic year 2019-2020, Marguerite Culot, Maximilian Frederik, Umloda Emad Ibrahim, Mostafa Khattab, Ewa Kataryna Kiszelka, Alix Lafosse, Peiwen Li, Yuan Liao, Leen M. Fouad, Donovan Mathews, Ying Sang, Clara Katharina Von Harling, Hsueh Liang Wong, Jianbin Zhang, Cameron McGrath, Greta Alexandra Bassett, Harriet Louis Bessant-Marsh, Samantha Carrick, Kim Eckersley, Alexander Hall, Christopher Stump, Ha Linh To, Inhe Yang and Jemima Presland. They were part of my first-year experience of implementing video essays as a creative assessment method. I am very grateful for their enthusiastic response to my invitation to create audiovisual criticism, and impressed by the quality of the work they produced. In their uncertainty lies my learning experience, the one that encourages me to keep engaging with this creative assessment method, and to produce them for various purposes. They have been my main partners in this collaborative task of working together towards finding some academic room for audiovisual criticism. They have been active participants in the learning and teaching of the study of film through film. My deepest gratitude also to all those colleagues who have been great sources of inspiration and supportive of my creative initiatives, starting from Prof Lindiwe Dovey. Many thanks to her and the whole Screen Worlds Team. I am so grateful to fellow colleagues at the School of Arts in SOAS, such as Prof Shane McCausland, who enthusiastically embraced and shared my interest in recursion, Dr Caspar Melville, Prof Lucy Duran, and Dr Morgan Davies, who welcomed me to a sonic discussion to share my experience teaching (or rather, being taught) video essays. I further thank the SOAS Decolonising Working Group. I am also grateful to Bartolomeo Meletti, for his eagerness to join me in the challenging endeavour of creating a guide to make video essays. Finally, I would like to thank the anonymous peer reviewer of this article, for their thorough feedback and generous engagement with my work.

\begin{abstract}
This article seeks to foster reflection on film pedagogy and research, encouraging academics to engage in artistic research and teaching methods. It specifically focuses on the video essay as a teaching and learning method, one that requires the willingness to take risks, but also, that can lead to a transformative experience in a still hierarchical educational system. The increasing openness to video essays in film journals shows an awareness of the way in which artistic research may contribute to decolonise academia. The practice of video essays leads to an inclusive, collaborative and polyphonic research environment, which dismantles the idea of a film canon. It contests the privileged position of the written 'text', when this is just understood as the written word. It also contributes to blurring the distance between the status of students and that of researchers. It invites them to assimilate work practices, curating and filmmaking, which sometimes happen simultaneously, curating through filmmaking. This article shares the example of the design of the video essay as a creative assessment method for two film modules in the MA Global Cinemas and the BA Creative Arts at SOAS, University of London. It stresses the importance of connecting research, practice and teaching, that is, the recursive study of film through film. It suggests that through making video essays class members become co-curators of the course, where learning is a multi-directional and collaborative experience.
\end{abstract}

Keywords: video essay, audiovisual criticism, recursion, decolonising curriculum, artistic research. 


\section{Introduction}

This article seeks to foster reflection on film pedagogy and research, encouraging academics to engage in artistic research (AR) and teaching methods. It specifically focuses on the video essay as a teaching and learning method, one that requires the willingness to take risks, but also, that can lead to a transformative experience in a still hierarchical educational system. The increasing openness to video essays in film journals shows an awareness of the way in which artistic research may contribute to decolonise academia. The practice of video essays leads to an inclusive, collaborative and polyphonic research environment, which dismantles the idea of a film canon. It contests the privileged position of the written 'text', when this is just understood as the written word. It also contributes to blurring the distance between the status of students and that of researchers. It invites them to assimilate work practices, curating and filmmaking, which sometimes happen simultaneously, curating through filmmaking.

AR forges an active learning environment where students become co-producers of knowledge, co-curators of global stories of cinema, informed by their diverse backgrounds. This is why, inspired by Lindiwe Dovey and Ifeanyi Awachie's reflection on decolonising pedagogy, I hereafter refer to students (and tutors) as "class members" (Dovey \& Awachie, 2019). This is a term inspired by Paolo Freire's emblematic book, Pedagogy of the oppressed, which calls for an understanding of all class members as both teachers and students, simultaneously, instead of as binary opposites (Freire, 2018[1970]). Reading the latest edition of Freire's book, published in celebration of the fiftieth anniversary of its first publication in Portuguese in 1968, is particularly striking for the actuality of the proposal. Freire demanded a view of students as reflexive "transformers of the world", based on praxis, that is, action (Freire, 2018[1970], p. 27-29). This, as Donaldo Malcedo notes in the introduction to the 2018 edition, contrasts with a "digestive concept of knowledge" where students eat, digest and then vomit (in exams) the knowledge transferred from tutors (Freire, 2018[1970], p. 28-29). As universities seek formulas to try to decolonise the curriculum, it is as pertinent as ever to revisit Freire's work, written in a context in which African countries were becoming independent following centuries of colonialism. Freire convinced that action was transformative and able to forge a new situation, "one which makes possible the pursuit of a fuller humanity" (Freire, 2018[1970], p. 47).

In the context of film and broader creative and cultural industries, we may then wonder: How can transformation be achieved, and contribute to decolonising the curriculum? How can film courses be designed in order to foster such transformation? What is the role of artistic research in and beyond the classrooms? My humble attempt to engage with these challenging questions is based on my first experience in designing creative assessment methods for two brand new film modules for the MA Global Cinemas (now merged with Global Creative and Cultural Industries) and the BA Creative Arts, at SOAS, University of London, in the academic year 2019-2020. This was a very particular one all over the world, due to the disruption caused by the global pandemic COVID-19. Such circumstances have made as evident as ever the great potential in integrating digital technologies into the teaching and learning practices, and aware, at the same time, of the inequalities and diverse possibilities of access depending on geographic locations, among other social, cultural, economic, and political factors. Tutors have (had to) become students, enhancing creativity, searching for teaching approaches able to foster an interactive and inclusive learning environment, acknowledging the impact of the pandemic on the physical and mental health of all class members. I draw precisely on this 'reverse' in the teaching and learning direction, derived from the application of artistic research methods in my still early pedagogic career, which is both research- and practice-led.

While the focus in this article is thus on pedagogy, I emphasise the connection between research, practice, and teaching, 
that is, the study of film through film. This is what is named here as "recursion". This claims a kind of film education that embraces practice as key to the theoretical enquiry, not so much to prepare aspiring filmmakers for the industry, but to produce reflexive and recursive scholarly work through artistic practice-based research. Criticality results then from a close engagement with and manipulation of the film medium, or as Jyoti Mistry and Tanja Sakota put it, interacts with the visual medium (2017, p. 115). It invites students to interrogate film theory through practice, through audiovisual criticism in multiple formats. I start by framing artistic research as a site of decolonisation, to then examine language in artistic research, specifically in video essays. This is illustrated through a closeup of the design of video essays as creative assessment methods in two film courses in the School of Arts at SOAS, University of London. I hope to shed light on the opportunities, challenges and implications of AR and practice-led teaching methods. By sharing the experience of implementing video essays as creative assessment methods at SOAS, from their design to their evaluation by class members, I attempt to offer some guidance to scholars and class members willing to adopt these methodologies. It addresses a series of points to be considered, such as the rationale behind the adoption of creative assessment methods; the consequent need to rethink the learning outcomes and marking criteria; the clear, open and inclusive design of assessment briefs for students with different backgrounds and skills; the technical support required, and the way of submitting and assessing the work by students. It further invites for feedback from fellow creative researchers who are already engaging in these practices. In other words, this article wishes to foster a collaborative and dialogic space for reflexivity on teaching practices and their links to AR.

\section{Artistic Research as a Site for Decolonisation}

AR works with an artistic multi-media language, whose scope is under continuous exploration. Before examining such language, it is worth reflecting on the potential implications of AR. This is not just a methodology, but a "mentality" (Van Brummelen and de Hann, 2011, cited in Mistry \& Andrew, 2017, p. 130), and more specifically, a decolonial mentality embodied in practice. It involves a kind of action that can lead to activism, or rather, artivism, one that troubles what Freire referred to as digestive modes of knowledge or "banking education" (Freire, 2018[1970]). As Ava DuVernay notes, "activism is inherently a creative endeavour. It takes a radical imagination to be an activist, to envision a world that is not there" (cited in Dovey, 2020, p. 2). AR constitutes then an active learning strategy, which requires a careful design (and curation) by educators. This is a time-consuming and challenging endeavour that many scholars are still hesitant to engage with (hooks, 1994, p. 204-205). It is also one that may lead to painful experiences, and to the brave acknowledgement from tutors to be in a vulnerable position. This can result from bringing our lived experiences, and by welcoming knowledge exchanged equally between learning partners, tutors and students, for instance (hooks, 1994; Dovey, 2020). "When professors bring narratives of their experiences into classroom discussions it eliminates the possibility that we can function as all-knowing, silent interrogators" (hooks, 1994, p. 21). Instead, vulnerability can foster a self-reflexive, safe, and inclusive learning environment, where class members' interactions are based on mutual respect. This can further create "cultures of reciprocity and generosity" (Dovey, 2020, p. 20).

An increasing number of recent publications have examined the way in which AR may contribute to the decolonisation of academia (Mistry \& Sakota, 2017; Mistry \& Andrew, 2017; Grant \& Price, 2020; Dovey, 2020). AR problematises hegemonic modes of knowledge, challenges and even contributes to the "unlearning" of the film canon and conventions (Mistry \& Sakota, 2017, p. 116-117, Mistry \& Andrew, 2017, p. 124). In 2012, Andrew Myers, then co-editor-in-chief of 
MEDIASCAPE1, suggested that the video essay specifically, had "the greatest potential to challenge the now historically located text-based dominance of the appraisal and interpretation of film and its contextual cultures" (Myers, 2012). Similarly, Dovey suggests visual language is "more accessible in many ways than the abstruse written language dominant in the academy - and which tends to be English" -, adding that "it can encourage decolonial thinking, for instance through storytelling and curating, therapy and healing, through using multiple language" (Dovey, 2020, p. 22).

The video essay, as artistic research, has a transformative potential, one that is necessary to "revitalise" film education by decolonising it (Mistry \& Sakota, 2017, p. 118-119). David A. Bailey, director of the International Curators Forum, is convinced that "decolonization can only happen within a discourse that has a real and lasting relationship with practice" (Bailey, in Grant \& Price, 2020, p. 11). One of the ways in which art may contribute to the decolonisation of the curriculum is through affect. Dovey and Awachie (2019) stress the way in which AR brings emotions and storytelling to the classrooms, inviting us to ask ourselves: "How can we ensure that class members engage with content in emotional as well as intellectual ways?" (Dovey \& Awachie, 2019). Smiljana Gilsovic's reflects about this potential audiovisually, through her video essay Choreography for Moving Image (2020). It explores the way in which spoken text and moving image can forge an intimate, affective and haptic understanding of "the interrelationship between ourselves, our bodies and the environment" (Glisovic, 2020). Catherine Grant and Dorothy Price interview various art historians, collectors, museum directors, artists, and writers to collectively find different approaches towards the decolonisation of the art history curriculum (2020). Ultimately, what they question is what we may be able to do as teachers, scholars and curators, or all of that simultaneously or separately, to respond to the global call for decolonisation (2020: 9). This article seeks to further address this question within the field of film and screen studies, hoping the experience shared here can be transferred to other arts and creative industries. I focus on two work practices in the university classroom: curation and video-making (a contemporary term for filmmaking in the era of digitalisation) ${ }^{2}$, which sometimes happens simultaneously, curation through video-making.

"Teaching is a form of curating stories" (Dovey, 2020, p. 20). It involves an "articulatory practice" (Laclau \& Mouffe, 2001[1985], p. 96), that is, a connection and organisation of different elements for a particular purpose. Inevitably, not all existing elements make it to such curation. By selecting readings, theories, key moments in history, and key authors, a whole range of aspects are "disarticulated" (Laclau \& Mouffe, 2001[1985]). When Lindiwe Dovey advocates for the "curatorial turn" in teaching (2018), she is inviting educators to acknowledge the creative work involved in the design of film (or any other) syllabus. This should be, as she knows, "explicitly presented to students as a subjective selection of material, not as something objective" (2020, p. 20). It should also be conceived as incomplete, as a work-in-progress, to be completed, questioned, and contested, that is, transformed, by students. When teachers embrace the curatorial turn, instead of positioning themselves as experts, as voice-of-God narrators, there is room for broader diversity and dialogue in the classroom (Dovey, 2018). Class members become then co-curators, bringing their own curatorial voices, collectively and collaboratively designing, creating, and contesting the curriculum. This can only occur when different forms of invitations to curate their own stories are created, and when there is acknowledgement of such collaborations. This may happen through explicit invitations in the syllabus (see Dovey, 2020), interactive lectures, seminars, or curatorial exercises

1 This was the first gold open access peer-reviewed digital journal of film and media studies, and one of the first to embrace non-traditional multimedia format. Its latest issue was published in 2018. 
in class, as well as through mid-term student feedback and course evaluation surveys. Such collective co-curation results from a multiplicity of subjectivities present in the classroom, a deconstruction of the self, or as Dovey puts it, a "return to personal sources" (Dovey, 2020, p. 6).

This teaching approach can contribute to decolonising the curriculum, as it moves away from the "danger of a single story", borrowing Chimamanda Ngozi Adichie's words (2009). Within the field of art history, Bailey notes how "a decolonized art history should always include multiple narratives so that it's about different histories..." - or as Dovey suggests, herstories $^{3}$ (Dovey, 2018) - "... and not a story that becomes the canon" (Bailey, in Grant \& Price, 2020, p. 10). Similarly, Tim Barringer suggests that diversification of voices is crucial to the decolonisation of the discipline (in Grant \& Price, 2020, p. 12). In their audiovisual text about Decolonising Pedagogy, Dovey and Awachie (2019) invite educators to ask ourselves: what sources do we provide, or could we provide to allow class members to curate the modules themselves? Beyond the aforementioned invitations to refer to further film titles and theories either through the spoken or written word, I would like to suggest here curation can also happen through video-making. In fact, Dovey wonders "... why can filmmaking, film curation, and film criticism not co-exist?" (2019, p. 479). Class members can be invited to engage with the course creatively, "thinking through the visual" (Maharaj cited in (Mistry \& Andrew, 2017, p.125) and thinking through making. In the field of art history, Pamela N. Corey suggests that decolonisation "involves engaging in the work of decentralizing and reconfiguring modes of creating, representing, and disseminating knowledge" (in Grant \& Price, 2020, p. 19). This is how the integration of artistic research should be conceived in pedagogy. Class members can curate their own stories of film through audiovisual criticism, informed by their individual yet located positionalities, diversifying the focus, priorities, and perspectives. Curators are storytellers. Filmmakers are storytellers. In fact, several filmmakers in Senegal and West Africa, more broadly, where orality has a crucial historic role, have referred to themselves as modern griots, or as Melissa Thackway puts it, as "screen griots" (2003, p. 48). Filmmakers from these regional backgrounds embrace, adapt and enhance oral tradition through the film medium. In an interview with June Givanni, Djibril Diop Mambéty, a leading Senegalese filmmaker, director of the internationally acclaimed Touki Bouki/ The Hyena's Journey (1973) said: "the word griot.. is the word for what I do and the role that the filmmaker has in society... the griot is a messenger of one's time, a visionary and the creator of the future" (cited in Thackway, 2003, p. 58). Ousmane Sembène, another key name in the history of cinema, also from Senegal, stressed how the film medium could contribute to the decolonization of minds, through an inward gaze, embedded in a particular (postcolonial) context, thus targeting African audiences (Sembène in Fofana, 2012, p. 7). It does not seem too risky then to suggest connecting these two, and see in filmmaking a creative space to co-curate the stories being taught and learned in and beyond the classrooms.

Engaging with bell hooks (1994) and Dovey and Awachie's reflection on the importance of vulnerability, by questioning ourselves: how would we describe "the story of how we came to the subject we currently teach and study"? (Dovey and Awachie, 2019).

I feel it is time for me to share my own positionality and experience in relation to AR. As a storyteller, it is difficult to look back at those key moments that may have motivated the initiative to design the video essay as a creative assessment method for my first year teaching at SOAS. My intention here is to briefly share some lived experience to enable readers to follow my journey and understand some of the sources that may have informed it. As an undergraduate student in University of Seville, I soon became aware of the misrepresentation

3 To which we could further include "theirstories" (for non-binary people) or even, "ourstories" to appropriate such stories. 
in the media. I focused specifically on the case of Africa, a continent that was physically so close to my hometown and yet so distant, or completely absent in our curriculum. I was fortunate to be granted an Erasmus grant to complete my final year at the University of Sussex, and to be taught Documentary Filmmaking by Professor Lizzie Thynne. I was fascinated by her ability to engage us critically with the different modes of representation. I became particularly interested in reflexive documentaries and 'hybrid' forms where filmmakers questioned their own objectivity as representers, such as in Trinh Minh-ha's Reassemblage (1982). As soon as I was back in Seville, in 2010, when irregular migration was attracting a huge media attention, I felt the need to make a documentary about migration in Spain. This was entitled Témoignages de l'autre côte/Testimonies from the other side, which would eventually be selected as the national winner for Spain for the European Charlemagne Youth Prize, for the contestation offered to hegemonic representations of Africa in Spanish media. This student-project has greatly shaped my whole career. When I went to SOAS as a postgraduate student, I was very possibly still unaware of the impact that the course Aspects of African Film and Video (now named 'The Story of African Film') would have on my professional and personal life. Carefully curated by Professor Lindiwe Dovey, who I now have the pleasure to work with, the course made it clear that the hegemonic history of film had marginalised many film cultures, and that film narrative was as diverse as contexts of production. I have ever since immersed myself in a triangle composed of practice, research, and pedagogy. During my doctoral thesis, I used a range of artistic research methods (maps, still and moving image, etc.). However, as Myers also notes, sometimes this visual material became just an appendix to the argument, at risk of not being seen (Myers, 2012). In my personal case, I had to ensure ideas were communicated through the written word, but at the same time wondered what could be done to integrate audiovisual criticism in academia. Video essays still struggle to find a scholarly space. They do not seem to enjoy the same legitimacy as written text. However, as Shane McCausland notes, there is a "growing interest in mediality" (2019, p. 158), and a large number of scholars who are building such legitimacy from the grassroots, through thinking through making, such as Catherine Grant, Christian Keathly, Shane O'Sullivan, Thomas van den Berg, and Miklós Kiss, to name a few. In fact, these have curated two online resources entirely devoted to video essays: The Videographic Essay: Practice and Pedagogy (Keathley, Mittell and Grant, 2019) and Film Studies in Motion: From Audiovisual Essay to Academic Research Video (van den Berg \& Kiss, 2016).

The opportunity for me to engage with video essays came in 2019, when I was fortunate to be appointed as Senior Teaching Fellow in film and screen studies at SOAS, in order to teach, among other, a couple of new film courses, surrounded by a highly prolific department of creative thinkers and practitioners, at the School of Arts (SoA). This was also the year in which the SoA saw the launch of the ERC-funded research project 'African Screen Worlds: Decolonising Film and Screen Studies', whose principal investigator is Professor Lindiwe Dovey, co-chair of the Centre for Creative Industries, Media and Screen Studies. This is actively engaging in $A R$ and free, open-access research outputs that are the fruit of collaboration and shared commitment to decolonise film and screen studies. SOAS has also a very active Decolonising SOAS working group, which I joined, thus broadening my knowledge on the collective effort to respond to such global call, from an interdisciplinary perspective. This context has contributed to the creation of a safe environment for early career researchers and educators like myself to be willing to take risks. The tribute to cinema within fiction has long existed, from Man with a Movie Camera (Dziga Vertov, 1929) to one of the latest examples being You Will Die at Twenty (Amjad Abu Alala, 2019); or biographies about filmmakers, such as Varda by Agnès (Agnès Varda, 2019), and Sembène! (Samba Gadjigo and Jason Silverman, 2015). The challenge now lied on engaging with another kind of video-making, for academic purposes. 


\section{Recursion: artistic research about/for/through/ nearby art}

Scholarly work on arts and creative industries is engaging with artistic research through examining creative multi-media arts-based languages able to convey the complex multi-faceted nature of arts and cultures. In the field of music, ethnomusicologists Richard Widdess, Christoph Finkensiep, and Martin Rohrmeier (2019), suggest a recursive elaboration of North Indian raga music through graphs. In contrast with 'formal' grammar, this is not context-free, and offers a representation of music considering various elements, such as notes, intervals, and the background structures of melodies. Art historian Shane McCausland (2019) examines "visual storytelling in artistic formats" in China around 1500 BCE. He refers to recursion as meta-narrative - "narratives within the narrative", where artifacts capture different forms of performances, or where a film like Still life (Jia Zhangke, 2006, China) is composed of multiple story-lines from within the frame of the characters and that of narrators (McCausland, 2019, p. 165-173); where there are "visual embodiments in narrative art" (McCausland, 2019, p. 174). Further terms include hypernarration, intertextuality and mise-en-abime. Such diversity in terminology echoes the various ways in which video essays are referred to, from audiovisual essay, to scholarly videos, and videographic film and moving image, for instance in the emblematic journal [in]Transition. Christian Keathley shrewdly notes that video essay is a term that still implies too much exposition, and that instead, scholarly video demands finding or inventing forms and language specific to video essays (Keathley, 2012). What I would like to explore here is precisely the kind of language in video essays, which I describe as recursive.

Keathley and Grant, pioneers in the field, have identified the video essay as "the [film] discipline's emergent scholarly form" (Grant, 2012). However, definitions are still quite broad. Video essays are "essentially a short analytical film about films or film culture... video criticism about the cinematic arts and, to a lesser extent, television" (McWhirter 2015, p. 369). Its development has to be seen in line with technological innovation, particularly, the internet. However, it is a form and language that advocates for the "agency of art" as a method, one concerned with "the critical interpretation of the work of art in all its visuality and materiality" (McCausland, 2019, p. 158). Film, in video essays, is "not simply about representation," but rather "a mode of knowledge production" (Mistry \& Andrew, 2017, p. 122).. Video essays involve some kind of compilation of already existing videos, that is, a supercut, mash-up, or remix video, practices that as Andrew McWhirter notes, have been conducted for decades (McWhirter 2015, p. 372), although not for academic purposes.

The challenge then lies on the framing of these audiovisual productions as scholarly work (Mistry \& Andrew, 2017: 123). Various creative scholars note how there are two main registers: explanatory (analytical and language-based) or "standard"; and poetic (expressive and which battles against language with a collage of images and sounds) or "nonstandard" (Grant, 2011; Keathley 2011 respectively, cited in McWhirter 2015, p. 371). Ian Garwood illustrates audiovisually, through a scholarly video, the audiovisual possibilities of video essays, and how these may not be sufficiently explored in voice-over driven video essays (Garwood, 2016). The challenge to him lies on the ability to engage with a kind of language where the spoken word is treated audiovisually (Lee, cited in Garwood 2016). In practice, this may be achieved through a creative manipulation and re-editing of footage to build a narration. This may contribute to counterbalancing the weight voice overs often have in the telling. However, while video essays do not need a voice over, "the choice to use it can be significant aesthetically, professionally, culturally, concludingly" (Garwood, 2016). Grant draws on Brad Haseman's proposal of a "performative" paradigm, where the reflection on arts is performed rather than written about. This resonates with Trinh Minh-Ha's self-reflection on representation, as 
"speaking nearby", which she performs in her reflexive ethnographic film Reassemblage (1982). This is indeed a pioneering (although not first) essay film, where different sounds, images, and postproduction decisions are contributing collectively to the making of the argument.

Building on Grant's understanding of artistic research as "performative" (2016), I suggest we refer to its language as recursive, a kind of recursion which is transformative and/as performed for academic purposes. Video essays invite us to "'write using the very materials that constitute our object of study: moving images and sounds" (Keathley, cited in Garwood, 2016). It encourages video-makers to engage with it haptically, affectively, that is, both intellectually and emotionally. It creates audiovisual knowledge through the audiovisual medium, that is, narratives about narratives, at the same time integrating the lived experience of the video-makers. To these multi-layered narratives both as an object and process, there are further inclusions of narratives when these video essays are included in the classroom. They actively create knowledge by decentralising the narrative from the tutor to the students. That is, as video-makers, students become creative class members, agents of knowledge, and co-curators of the stories of film learned - and not necessarily being taught - in class. There lies the great transformative potential of video essays to decolonise the curriculum.

\section{Close-up of the design of video essays as a creative assessment method in the School of Arts at SOAS, University of London}

Dovey illustrates the reciprocal learning process that takes place in the classroom when she says: "by teaching films made by Africans I get to be a constant student of African film-making" (Dovey, 2020, p. 10). This has certainly been the case for all courses I have taught. What I was possibly not aware of was the extent to which I would learn from my class members about video essays as creative assessment. This is thus an article that pays tribute to such "reverse" in the teaching direction, from students to tutors, instead of the other way around. They have become, I am not sure if to their knowledge, co-curators and co-designers of the creative assessment methods in the upcoming year(s), as well as partners in my learning experience about this kind of artistic research method. Despite my filmmaking background in a peer reviewed journal. This contrasts with the work by scholars who have inspired both my enthusiasm for applying this creative assessment method and informed this article. My aim here is also to acknowledge the transformative work creative scholars are conducting by thinking through making and by sharing such practical thinking through both pedagogy and literature. I do this by sharing my own experience of "being taught" by my class members about how to make video essays. In so doing, I ultimately aim to thank my undergraduate and postgraduate class members of 2019-2020. As my own teaching methods evolve and I further develop the video essay as a creative assessment method, I will always look back fondly at the collaborative learning experience shared with the first classes in 2019-2020, who engaged so enthusiastically with my teaching method when it was still in its earliest stage. Not only do I feel more prepared to keep engaging with this creative assessment method, but also, I feel motivated to make video essays myself, both for research and teaching purposes. This has become as timely as ever, in a period of global pandemic where universities are embracing creative teaching methods innovatively integrating digital technologies. I start by identifying some of the points I initially considered when designing this creative assessment method, to then focus more thoroughly on what I learned from my class members.

Several scholars have already shared their insightful experiences of teaching and assessing video essays (Becker \& Copple Smith, 2013; Keathley, 2012, Marshall; 2012; among others). Such reflections raise very important questions around the pedagogical benefits of video essays, technological and copyright considerations, and marking criteria. These were 
also some of the aspects I considered when designing this creative assessment method. The production of video essays was just one of the three assessment methods of the firstyear undergraduate course 'Introduction to Film Language, History and Theory' in the BA Creative Arts. This was open as an option, and the class indeed greatly benefitted from the interdisciplinarity of its members. It was also one of the three assessment methods of the postgraduate course 'Film and Screen Studies: Past and Present', also available as an optional module for class members from different disciplines, who also highly enriched the course. It was conceived as an "in-class individual 10-minute presentation", in order to be as inclusive as possible and be allowed to consider multiple formats, other than the video essay. I also aligned with the view of the act of lecturing as a multi-media performance, thus similar with the video essay (McWhirter, 2015; Myers, 2012). However, class members were thrilled to produce a video essay, and there was just one who instead delivered a power-point presentation which included some videos. ${ }^{4}$

I was mainly concerned with offering the class members the opportunity to engage with artistic research, but very uncertain about the degree of enthusiasm - or anxiety! - it would foster. This led to a rather open assessment brief, where there was a "gentle invitation" to produce a video essay:

You are welcome and encouraged to enjoy this opportunity to adopt a more creative response to the module through, for example, a short film, a series of images/stills, a small curated project, or an audiovisual essay. This will allow you to demonstrate awareness, understanding and an efficient application of innovative research methods for the creative industries. The presentation should include at least one critical analysis of a film scene of your choice, although this should not be from an essential viewing in the module syllabus. Presentations should last 10 minutes. There will be time for questions and feedback from the students and tutor at the end of each presentation.

The brief included some examples of video essays, and there were further examples and readings in the course syllabus, some of which we briefly discussed in class. Like Keathley, I also considered the essential question to be "conceptual" rather than technological (Keathley, 2012). Whilst I offered to help with editing, for instance, I emphasised they would mainly be assessed on their ability to make an argument, audiovisually, and their willingness to take risks. Such marking criteria, complemented with generic grade boundaries, was included in the brief. It was aligned with the learning outcomes of the course, with one of them in bold and emphasised also orally, in class: "On successful completion of this module students ${ }^{5}$ will be able to understand and apply different methodologies for the writing and thinking about film, including innovative research methods for the creative industries, such as audiovisual criticism." And that was it. We devoted a two-hour session workshopping video essays, when they were still in their pre-production phase, and a few class members booked some one-to-one tutorials to further share their ideas, plans, and narrations with me.

In the last teaching week, the reverse of the teaching direction became clear. Students "took the stage" and became the curators, the storytellers of film. We organised a kind of mini-festival, where class members introduced their video essays, which were then played. I then invited fellow class members to provide feedback, hoping by then a safe learning environment had been built, fostering an enriching peer learning community. Later, I gave feedback myself, emphasising what worked well and suggesting areas of improvement. The work produced was fascinating. I was highly impressed by

4 There were also a few non-submissions, mainly from class members who had not submitted any written work. 
the range of creative approaches. Their engagement made evident that I still had to polish this method quite significantly. In an attempt to be as concise as possible, I have classified here what I consider to be the main findings or learning points. By noting such areas of improvement, I seek to initiate my practice-based research around how to improve them, aware that this is still an ongoing task that can only be accomplished collaboratively.

\section{a) Enthusiastic engagement with creative assessment methods}

I had not foreseen the high degree of enthusiasm from class members, regardless their uncertainty around what was expected from them in such creation. They excelled at producing creative work. They became their own storytellers of their-stories of cinema, including further titles from across a wide range of regions, some of which were addressing their own film cultures, such as The Czech Republic, Egypt, and South Korea. Topics included animation, queer cinema, haptic visuality, colour-coding, humour as a way of overcoming censorship, feminism, hierarchy, patriarchy, migration and exile, and realism in cinema. Some of the video essays were closer to doctoral research than to postgraduate studies, thus confirming the need to diffuse the boundaries between students and researchers. One such impressive example was a postgraduate video essay about Nihongami, the term for traditional Japanese hairstyles, which explored the way in which hair served as a means of communicating the wearer's social status in the Tokugawa period (1603-1868). The work produced confirmed the transformative potential of video essays. It illustrated the way in which artistic research can contribute to decolonising the curriculum. The quality was such that my colleagues in the SoA decided to establish an annual prize to the best video essay, and another to the best podcast, as my colleague Dr Caspar Melville had had a very similar experience in the creative assessment methods in the MA he convened.

\section{b) Narration and Recursive Language}

After careful deliberation, the award was given to a postgraduate class member who had taken a particularly innovative (and risky) creative approach. Donovan Mathews had produced a multi-layered piece, where there was an aesthetically significant use of the voice over. Through this, the argument was not just exposed, orally, but performed, audiovisually, recursively. The nomination praised such a creative approach:

Despite the difficulty of nominating an award-winner for the best video essay, since there were very strong submissions by a range of undergraduate and postgraduate students, Donovan's work stood up for its remarkable originality, creativity and reflexivity. Building on Trinh T. Minh-ha's video essay Reassemblage, Donovan's multi-layered narrative structure was particularly strong at explaining theory through showing it. The reflection on the myth of realism in cinema was complemented by a recreation of Trinh T. Minh-ha's work on Donovan's gentrified neighbourhood. It was then that Donovan acted like a benshi, VJ or spoken word artist, in order to question the extent to which film represents reality. Such an original recursive approach which demonstrated his ability to take risks and critical understanding of the creative potential of the video essay as a method!

This contrasted with the rest of the essays, which relied significantly on narration, and thus an explanatory mode, as further scholars note more broadly (Keathley, 2012). This reliance on the voice over may result from the effort to adapt a written essay to the screen, which is already quite challenging. In fact, in a UCLA graduate course convened by Professor Janet Bergstrom, class members learn how to adapt their previously-written research papers into audiovisual form (Myers, 2012). A further degree of challenge arises when the piece is conceived audiovisually, from the beginning. This is disruptive even within 
the arts and creative industries courses in that it challenges the dominant hegemony of the written text. How to do this is still a task to continue exploring, through practice, and aware of the variety of forms and shapes it may take. As a filmmaker who has often been criticised for not including voice-over to contextualise her work, it was been very enlightening to see how this can also foster a space for decolonisation. Some class members were not comfortable with their voices being heard. One modified her voice through software. Another preferred to ask someone else to narrate for her. A French student felt more comfortable narrating in her native language, and decided to subtitle the film. This was particularly coherent in an essay on the sonic dimension of exile, leading to some kind of recursion, with further instances of recursion along the video essay. Arguably without her notice, she was further contributing to decolonising the curriculum, by moving away or even resisting to knowledge dissemination just in English.

\section{c) Further guidance, licence, and training}

Despite the excellent creative response from class members, what the experience made clear was the need to design, along this assessment method, a much clearer guide. With written essays, class members have more or less an idea of how to produce these, particularly at postgraduate level. The University offers a wide range of study skills helping class members with academic writing. This is not the case for video essays, and while this is a great opportunity for creativity, a lack of guidance can lead to "painful" experiences for all class members, including tutors. Further scholars have identified the need for training and specific resources for the making of video essays (McWhirter 2015, p. 373-374). Similarly, Keathley notes that even when "students' conceptual grounding is [now] solid, they still need a focused and concrete set of instructions for making their own work" (2012). They need examples. Quoting hooks, Dovey (2020) draws on the way in which teaching may sometimes be painful, in different ways. There was, indeed, some degree of pain when listening to class members about the amount of hours they had devoted to the making of the video essay. Some said they had stayed until very late at night trying to export their videos to then come across that painful message of "unknown error" or similar. As much as they were respectful and were saying this as a way of their sharing experience, I could sense and embody such pain, with flashbacks of my own editing experience as a filmmaker. I had warned them, but I had not really provided much formal technical assistance. I had offered this, but by the time they were ready to edit it was probably too late to find some office hours for it. This was however counterbalanced with a clear sense of pride, sometimes explicitly vocalised by class members. ${ }^{6}$ Despite the learning by doing approach and opportunities for self-teaching and peer learning in the implementation of this creative assessment method, training is necessary to ensure an inclusive teaching environment, aware of equality and diversity. This is why, based on the experience this year, I decided to put together an introductory guide about how to make video essays, in an effort to acknowledge and synthesise the pioneering work on this field. ${ }^{7}$ I also requested some licence and training, at least to provide some basic notions for students willing to engage with the assessment at high technical standards.

\section{d) Inclusion of a supporting statement}

The reliance on narration may also have been due to the fact that video essays were solely marked based on the produced

6 Listen to some positive feedback in the SOAS Podcasts (2020). 'Video Essays as a Creative Method of Assessment'. School of Arts SOAS Podcasts Series, 2. Available online (27.05.20): https://soundcloud.com/soas-university-of-london/videoessays?fbclid=IwAR3wNehcivYJF5k8IXCiBpN8UNKKOkds3YGY_S9uWm03Pgv-iu9PtWGNYel

7 When asking a friend about copyright considerations to include in this guide, a further opportunity came up to collaboratively write a guide and make it more broadly available as a teaching resource published on Learning on Screen, available online (15.10.20): https://learningonscreen. ac.uk/guidance/introductory-guide-to-video-essays/ 
piece. I had invited class members to be as experimental as they wished, and justify their aesthetic choices orally, during the class presentations. However, I suspect the inclusion of a narration could foster clarity in the argument, in a way audiovisual language may not be able to perform so efficiently. Because assessments are externally examined, I had uploaded their video essays to One Drive, since the TurnItIn submission was empty. However, I included a written version of the feedback I had given in class. A written supporting statement explaining the rationale behind the video essay could have facilitated the moderation by external examiners, as well as encouraged further creative engagements with the recursive language of video essays. This is one of the aspects included in the guide.

\section{e) Copyright considerations}

Another very important dimension implied in the application of this creative assessment was the legality of the process of making video essays. This very often requires sourcing the video with copyrighted creative work, which students found themselves downloading not so "lawfully", even if there was a sense this was used "fairly", for learning purposes. It was precisely my own research on this front which would then foster the production of the introductory guide on how to make video essays. This includes a section on copyright and creative reuse, written by Bartolomeo Meletti, the Copyright Services Delivery Manager of Learning on Screen and Creative Director for CREATe, the UK Copyright and Creative Economy Centre at the University of Glasgow, which has been further complemented by a couple of webinars on the matter for class members in 2020-21.

\section{f) Clarification of marking criteria}

A final area of improvement regards the marking criteria. Instead of including the generic SOAS marking criteria, this kind of creative assessment requires a much more deconstructed marking criteria. This should refer explicitly to the various tasks involved in the making of a video essay, with clear and inclusive language. Such criteria would contribute to reducing the uncertainty revolving around this creative assessment method. At the same time, whilst the screening of video essays in class followed by feedback was as enjoyable as enriching for the course, some class members were not comfortable with the public revelation of the grade boundary in which their work would fall. In fact, once I realised this (which was confirmed in one of the comments in the course evaluation surveys), I changed this immediately for the undergraduate "showcase", and instead told class members I would only indicate their grade boundaries if they wanted me to. These are just some of the many aspects I was taught by my class members.

\section{Conclusion}

This article engages with recent scholarly work about the transformative dimension of artistic research, and the way in which this may, recursively, through the film medium, contribute to decolonising the curriculum. Recursion is conceived here as the kind of artistic research performed in the thinking of film and screen media through the making. "Film as a language is not only about content and spectatorship but one where the instrument (film) is the vehicle for and of research itself" (Mistry \& Sakota, 2017, p. 113). This poses both a technical and theoretical challenge. It requires a theoretical grounding of both the kind of audiovisual language involved and the rationale behind its use (Keathley, 2012). Inspired by Dovey and Awachie's understanding of students as "class members" (Dovey \& Awachie, 2019; Dovey, 2020), it suggests that the integration of the video essays as a creative assessment method fosters a decentralisation of the voices and agents of knowledge within a classroom. Class members become co-curators, through making, as storytellers through the film medium. This can lead to the decolonisation of academia, by decentering references informed by 
different positionalities and involving affect in intellectual and critical thinking. It can further prompt a "reverse" in the teaching direction, where tutors are taught by students instead of the other way around. This is illustrated by a case study of two brand film courses in the School of Arts at SOAS, in an attempt to share experiences of artistic research in pedagogy. What this article has proved is that the adoption of such creative methods requires a willingness to take risks and to position ourselves as vulnerable class members. Catherine Grant, a pioneer creative researcher and agent of legitimisation of video essays, suggests that "signs of 'imperfection' may be key in defining the critical distance between audiovisual essays and the objects they study" (cited in Garwood, 2016). As I continue to deal with such imperfection and find creative ways of engaging further with this method, I cannot avoid thinking of Ousmane Sembène's concept of mégotage. This may prompt to be an encouraging concept for those creative thinkers - and may I say artivists - who might want to explore the aesthetic and transformative possibilities of video essays. Mégotage is the term Sembène used to refer to filmmaking, and the passion that makes it possible. It is composed of montage and bricolage, particularly in a postcolonial context (Adesokan, 2011, p. 22). May we then continue to practice some mégotage, as we seek formulas to transform education, and along with it, our positions in the world.

\section{References}

Adesokan, Akinwumi (2011). Postcolonial Artists and Global Aesthetics. Bloomington: Indiana University Press.

Adichie, Chimamanda Ngozi (2009). 'The danger of a single story'. TEDGlobal 2009. Available online (25.07.20): https:// www.ted.com/talks/chimamanda_ngozi_adichie_the_danger of a single story/transcript?language=en
Becker, Christine and Copple Smith, Erin (eds.) (2013). 'Teaching Dossier: The Video Essay Assignment.' In Cinema Journal: The Journal for the Society of Cinema and Media Studies, 1(2), Spring/Summer 2013: http://www.teachingmedia.org/ the-video-essay-assignment-cinema-journal-teaching-dossier-vol-12l.

Callahan, Vick and Kuhn, Virgin (2016). 'Introduction to Issue 11: The Video Essay: An Emergent Taxonomy of Cinematic Writing.' In The Cine-Files, 11, Fall 2016. Available online (03.07.2019): http://www.thecine-files.com/introduction-issue11/

Cox-Stanton, Tracy (2014). 'Welcome to Issue 7, "The Video Essay: Parameters, Practice, Pedagogy"'. In The Cine-Files, 7, Fall 2014 (05.09.2019): http://www.thecine-files.com/issue7introduction/

Diélcio Moreira, Benedito and Pinto de Oliveira, Pedro (2019). 'New ways of Communicating Science: The Audiovisual Scientific Essay Experience.' In Tecmerin. Journal of Audiovisual Videoessays, 2, July 2019. Available online (29.07.19): https:// tecmerin.uc3m.es/en/journal-2-4/

Dovey, Lindiwe (2018). 'Towards Alternative Histories and Herstories of African Filmmaking: From Bricolage to the 'Curatorial Turn' in African Film Scholarship'. In Harrow, Kenneth and Garritano, Carmela, (eds.). Companion to African Cinema. Oxford: Wiley-Blackwell: 467-485.

(2020). 'On Teaching and Being Taught: Reflections on Decolonising Pedagogy.' In PARSE-Intersections, (11). Available online (29.06.20): https://parsejournal.com/article/on-teaching-and-being-taught/ 
Dovey, Lindiwe and Awachie, Ifeanyi (2019). Decolonising pedagogy video. Produced by Chouette Films. September 2019. Available online (3.07.20): https://screenworlds.org/ resources/decolonising-pedagogy/

Finkensiep, Christoph, Widdess, Richard, and Rohrmeier, Martin (2019). 'Modelling the Syntax of North Indian Melodies with a Generalized Graph Grammar.' 20th International Society for Music Information Retrieval Conference, Delft, The Netherlands, 2019. Available online (13.07.20): https://zenodo.org/record/3527844\#.Xx7ycy-Q3q0

Fofana, Amadou T. (2012). The films of Ousmane Sembène: Discourse, culture, and politics. Amherst, N.Y.: Cambria Press.

Garwood, Ian (2016). 'The Place of Voiceover in Academic Audiovisual Film and Television Criticsm.' In NECSUS, Autumn 2016. Available online (03.07.20): https://necsus-ejms.org/ the-place-of-voiceover-in-audiovisual-film-and-television-criticism/

Grant, Catherine (2016). 'The audiovisual essay as performative research.' In NECSUS, Autumn 2016. Available online (07.09.19): $\quad$ https://necsus-ejms.org/the-audiovisual-essay-as-performative-research/

(2014). 'The Shudder of a Cinephiliac Idea? Videographic Film Studies Practice as Material Thinking.' In aniki: Portuguese Journal of the Moving Image, 1(1): 49-62.

Grant, Catherine and Kooijman, Jaap (2019). 'New Ways of seeing (and hearing): The audiovisual essay and television.' In NECSUS, Spring 2019. Available online (03.07.2019): https:// necsus-ejms.org/new-ways-of-seeing-and-hearing-the-audiovisual-essay-and-television/
Grant, Catherine, and Price, Dorothy (2020). 'Decolonizing Art History.' Association for Art History 43, February 2020: 8-66.

hooks, bell (1994). Teaching to transgress: Education as the practice of freedom. New York: Routledge.

Keathley, Christian (2014). 'Teaching Videographic Film Studies.' In The Cine-Files, 7, Fall 2014. Available online (06.10.2019): http://www.thecine-files.com/keathley/

(2012). 'Teaching the Scholarly Video.' In Frames Cinema Journal, 1(1). Available online (06.10.2019): http://framescinemajournal.com/article/teaching-the-scholarly-video/

Keathley, Christian, Mittell, Jason and Grant, Catherine (2019). The Videographic Essay - Criticism in Sound and Image. Available online (03.09.19). http://videographicessay.org/works/ videographic-essay/index

Laclau, Ernesto and Mouffe, Chantal (2001[1985]). 'Beyond the Positivity of the Social: Antagonism and Hegemony.' In Hegemony and socialist strategy. London, New York: Verso: 93-148.

Marshall, Kelli (2012). 'Video Essays in the Cinema History Classroom.' In Special Issue 'Film and Moving Image Studies Re-Born Digital?' Frames Cinema Journal, 1. Available online (02.09.2019): http://framescinemajournal.com/article/video essays-in-the-cinema-history-classroom/

Mathews, Donovan (forthcoming 2020). 'Embracing Nonsense: Narrative Form and Finding Meaning in Trinh Minhha's Reassemblage'. 
McCausland, Shane (2019). 'Intermediary Moments: Framing and Scrolling Devices across Painting, Print and Film in China's Visual Narratives.' In Wagner-Durand, Elisabeth et al. (eds.) (2019). Image - Narration - Context: Visual Narration in Cultures and Societies of the Old World. Heidelberg: Propylaeum: 157-175. Available online (20.07.20): https://books. ub.uni-heidelberg.de/propylaeum/catalog/book/399

Mcwirther, Andrew (2015). 'Film criticism, film scholarship and the video essay'. In Screen, 56(3): 369-377. Available online (02.07.20): https://academic.oup.com/screen/article-abstract/56/3/369/1860953?redirectedFrom=fulltext

Mistry, Jyoti and Andrew, David (2017). 'Pedagogies and practices of disaffection: Film programmes in arts schools in a time of revolution.' In Journal of African Cinemas, 9 (2-3): 119132.

Mistry, Jyoti and Sakota, Tanja (2017). 'Filmmaking as research: Pedagogy and practice.' In Journal of African Cinemas, 9 (2-3): 113-118.

Mulvey, Laura (2006). Death $24 x$ a second: Stillness and the moving image. London: Reaktion Books.

Myers, Andrew (2012). 'Click Here to Print This Video Essay: Observations on Open Access and Non-Traditional Format in Digital Cinema and Media Studies Publishing.' In Special Issue 'Film and Moving Image Studies Re-Born Digital?' Frames Cinema Journal, 1. Available online (02.09.2019): http://framescinemajournal.com/article/click-here-to-print-this-video essay/

Rascaroli, Laura (2017). 'Framing: Looking for an Object, or The Essay Film as Theoretical Practice.' In How the Essay Film Thinks. Oxford: Oxford University Press: 165-186
SOAS Podcasts (2020). 'Video Essays as a Creative Method of Assessment'. School of Arts SOAS Podcasts Series, 2. Available online (27.05.20): https://soundcloud.com/soas-university-of-Iondon/videoessays?fbclid=IwAR3wNehcivYJF5k8IXCiBpN8UNKKOKds3YGY_S9uWm03Pgv-iugPtWGNYel

Thackway, Melissa (2003). 'Chapter 3: Screen Griots: Orature and Film.' In Africa Shoots Back: Alternative Perspectives in Sub-Saharan Francophone African Film. Oxford: James Currey: 49-92.

Trinh, T. Minh-Ha (1989). Woman, Native, Other: Writing PostcoIoniality and Feminism. Bloomington: Indiana University Press.

van den Berg, Thomas, and Kiss, Miklós (2016). Film Studies in Motion: From Audiovisual Essay to Academic Research Video. Available online (07.07.2020): https://scalar.usc.edu/works/ film-studies-in-motion/index 